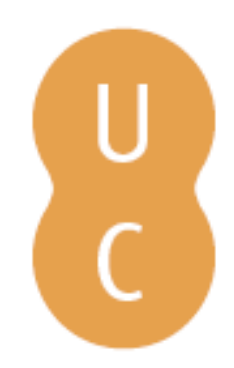

\title{
nommalina
}

\section{Estado novo e corporativismo: um programa de investigação em história económica e das instituições}

\author{
Autor(es): $\quad$ Garrido, Álvaro \\ Publicado por: Imprensa da Universidade de Coimbra \\ URL \\ persistente: URI:http://hdl.handle.net/10316.2/31620 \\ DOI: $\quad$ DOI:http://dx.doi.org/10.14195/978-989-26-0199-1_21 \\ Accessed : $\quad$ 26-Apr-2023 08:09:47
}

A navegação consulta e descarregamento dos títulos inseridos nas Bibliotecas Digitais UC Digitalis, UC Pombalina e UC Impactum, pressupõem a aceitação plena e sem reservas dos Termos e Condições de Uso destas Bibliotecas Digitais, disponíveis em https://digitalis.uc.pt/pt-pt/termos.

Conforme exposto nos referidos Termos e Condições de Uso, o descarregamento de títulos de acesso restrito requer uma licença válida de autorização devendo o utilizador aceder ao(s) documento(s) a partir de um endereço de IP da instituição detentora da supramencionada licença.

Ao utilizador é apenas permitido o descarregamento para uso pessoal, pelo que o emprego do(s) título(s) descarregado(s) para outro fim, designadamente comercial, carece de autorização do respetivo autor ou editor da obra.

Na medida em que todas as obras da UC Digitalis se encontram protegidas pelo Código do Direito de Autor e Direitos Conexos e demais legislação aplicável, toda a cópia, parcial ou total, deste documento, nos casos em que é legalmente admitida, deverá conter ou fazer-se acompanhar por este aviso.

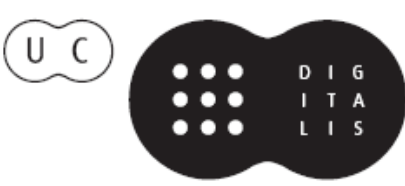


Maria Manuela Tavares Ribeiro

Coordenação

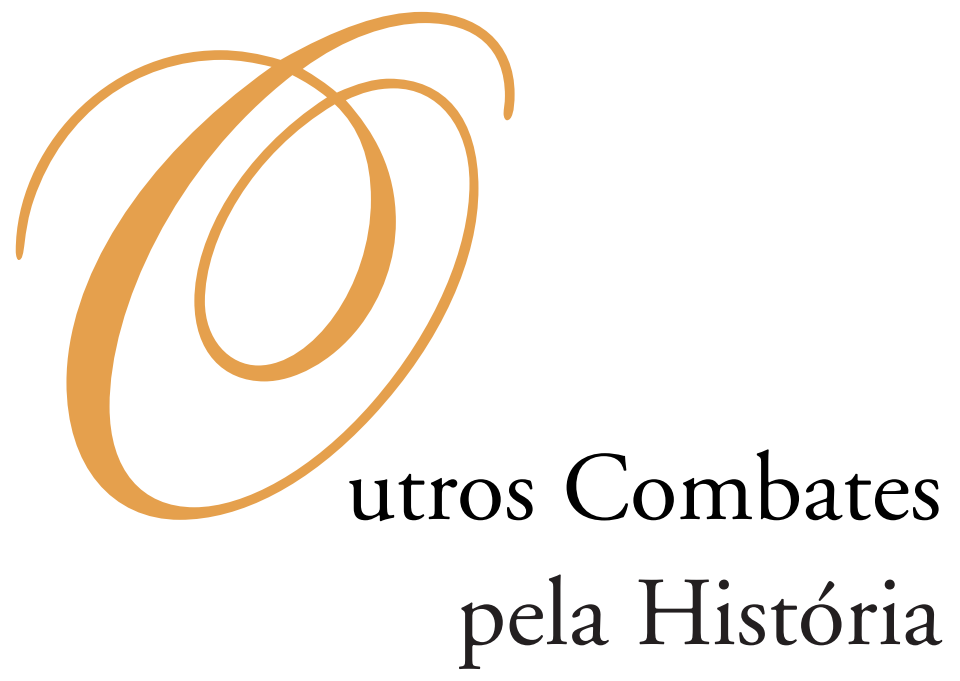




\section{COORDENAÇĀO EDITORIAL}

Imprensa da Universidade de Coimbra

Email: imprensauc@ci.uc.pt

URL: http://www.uc.pt/imprensa_uc

Vendas online: http://livrariadaimprensa.com

\section{CONCEPÇÃO GRÁFICA}

António Barros

\section{ORgANIZAÇĀO DOS TEXTOS}

Isabel Maria Luciano

Marlene Taveira

PRÉ-IMPRESSÃO

António Resende

Imprensa da Universidade de Coimbra

EXECUÇÃO GRÁFICA

SerSilito • Maia

ISBN

978-989-26-0041-3

DEPósito LEGAL

OBRA PUBLICADA COM O APOIO DE:

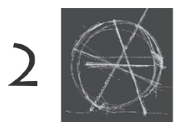

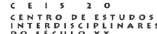

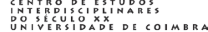

FCT Fundação para a Ciência e a Tecnologia

MINISTÉRIO DA CIÊNCIA, TECNOLOGIA E ENSINO SUPERIOR Portugal

Programa Operacional Ciência, Tecnologia, INOVAÇĀo DO QUADRo COMUNITÁRIO DE APOIO III

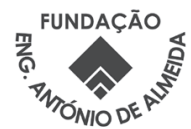

C JULHO 2010, IMPRENSA DA UNIVERSIDADE DE COIMBRA 
Maria Manuela Tavares Ribeiro

Coordenação

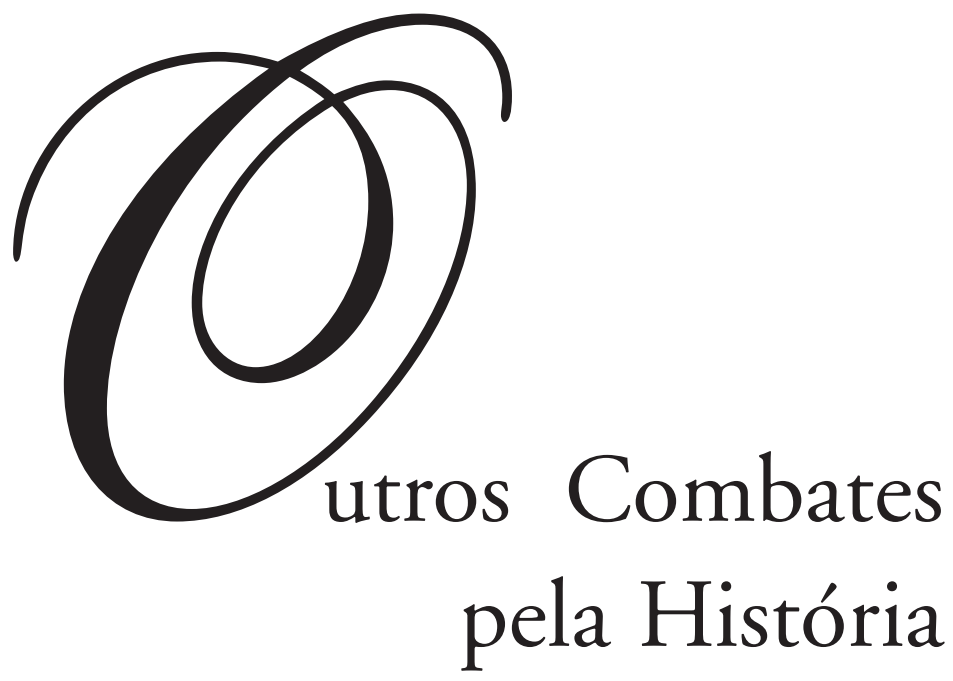

- colmbra 2010 
História e Organizaçôes

ECONÓMICAS E SOCIAIS 


\section{Álvaro Garrido}

\section{ESTADO NOVO E CORPORATIVISMO. UM PROGRAMA DE INVESTIGAÇĀO EM HISTÓRIA ECONÓMICA E DAS INSTITUIÇÕES}

\section{O corporativismo como objecto historiográfico}

Nos países da Europa do sul que conheceram regimes autoritários de inspiração fascista, a palavra corporativismo tornou-se hiper-referencial do ponto de vista sociológico e sub-analisada do ponto de vista histórico. Para este desequilíbrio concorrem, certamente, apropriaçôes ligeiras da memória dos "corporativismos históricos»: por um lado, o carácter neocorporativo da maioria dos regimes democráticos europeus nos quais a concertação dos interesses ocupa um lugar de relevo no palco social e mediático $^{1}$; por outro, a filiação de valores sociais e de comportamentos de diversos grupos profissionais ou de interesse numa arreigada tradição corporativa da sociedade portuguesa, vício cultural alegadamente adquirido na longa experiência do corporativismo salazarista.

O estudo do corporativismo autoritário europeu do século XX exige um esforço comparativo, de modo a proporcionar interpretações caso a caso e Estado a Estado. A análise das experiências históricas de implantação dos sistemas corporativos parece-nos um método fundamental para esbater as explicaçôes generalizadoras da politologia, sempre demasiado preocupada em estabelecer taxonomias. Outra via de método - e outra cautela epistemológica — reside na necessidade de temperar a dogmática doutrinária e a ideologia política do corporativismo com um esforço de interpretação das suas finalidades instrumentais e de compreensão das singularidades nacionais dos sistemas políticos que se reclamaram «corporativos».

Neste como noutros temas de investigação histórica que exigem distinguir o discurso da prática (ou a realidade das meta-realidades), importa situar a nossa perspectiva de análise e esboçar uma problemática que, dada a densidade doutrinária dos discursos que comporta e os ardis da propaganda, exige especiais cuidados hermenêuticos. Um bom caminho de estudo, ainda pouco ensaiado, será o de comparar entre si, ou

\footnotetext{
${ }^{1}$ Sobre a problemática do neocorporativismo, vide a síntese de Vital Moreira, Auto-Regulação Profissional e Administração Pública, Coimbra, Almedina, 1997, pp. 144-149.
} 
entre as diversas experiências nacionais corporativistas, os usos políticos da ideia corporativa e dos aparelhos burocrático-institucionais que nela se apoiaram para cumprir, entre outras, as seguintes finalidades políticas: reorganizar a economia liberal debaixo dos interesses do Estado autoritário e das suas oligarquias; ordenar a sociedade de modo a prevenir a desordem pública e movimentos sociais hostis; impor sistemas de intermediação de interesses de forma a regular as relações entre o público e o privado no âmbito de instituições fortemente controladas pelo Estado.

Pôr em evidência o uso político e institucional do corporativismo implica tomar os sistemas corporativos como sistemas de «terceira via», fazendo fé na profecia doutrinal. Mas também exige privilegiar analiticamente o factor organização, principal imperativo doutrinário dos corporativistas, como se a organização corporativa fosse uma força autónoma que, pela mão do Estado, acabaria por dirigir os factores de produção e as próprias relações sociais ${ }^{2}$. A organização corporativa, com toda a sorte de organismos que dela fizeram parte, foi a mais saliente e inovadora criação institucional dos Estados corporativos no sentido de domesticar o capitalismo, compartimentando os interesses e impondo a colaboração entre «capital» e «trabalho» num plano nacional.

Fazer história do corporativismo obriga, pois, a esforços redobrados no escrutínio das autenticidades. Tema ingrato e muito marcado pelas vicissitudes da memória histórica, dada a associação que sempre se estabelece entre a ideologia corporativa e os regimes fascistas, obriga a discernir as obscuras relações entre a consciência e a acção.

Teoria, doutrina, leis, e os mais diversos documentos que evocam o quotidiano burocrático dos organismos que funcionaram sob a égide do sistema corporativo, compõem uma assombrosa torrente discursiva. Trata-se de um imenso caudal de meta-fontes, nem sempre esclarecedoras do quotidiano das instituiçôes e das vicissitudes do "corporativismo real». Essas séries de documentação de carácter institucional, quando não se perderam nos labirintos das transições políticas e reformas do Estado, parecem ter sido destinadas a persuadir os contemporâneos do sistema corporativo acerca das virtudes da «ideia do século» - assim chamou Mihail Manöilesco ao «corporativismo integral e puro» ${ }^{3}$ quando o declarou o único sistema de ideias capaz de resolver a "questão social» herdada do século XIX.

Do outro lado do «objecto», amiúde inacessível pelo caminho das fontes, ficam as instituiçôes políticas, económicas e sociais criadas debaixo da doutrina corporativa — ou seja, o sistema e a organização, realidades que não coincidem de todo, conforme alertou Manuel de Lucena ${ }^{4}$.

As incoerências entre a teoria e a prática, as contradições dos corporativismos históricos da Europa de entre-guerras, em geral, e do sistema corporativo português instituído pelo Estado Novo, em particular, têm sido identificadas por historiadores, sociólogos e politólogos.

\footnotetext{
2 Cf. Pedro Teotónio Pereira, A Batalha do Futuro. Organização Corporativa, 2 aed., Lisboa, Livraria Clássica Editora, 1937, p. 108.

3 A expressão consta do próprio título da obra do autor romeno, muito divulgada em Portugal: Le siècle du corporatisme: doctrine du corporatisme intégral et pur, Paris, Félix Alcan, 1934.

${ }^{4}$ Manuel de Lucena, A evolução do sistema corporativo português, Lisboa, Perspectivas \& Realidades, 1976, vol. I, pp. 102-106.
} 
No caso português, tais evidências contraditórias têm-se revelado reconfortantes para o entendimento do corporativismo enquanto sistema, mas pouco estimulantes para o estudo histórico da sua experiência concreta. Nomeadamente, no que toca à acção quotidiana e ao impacto estrutural da miríade de organismos corporativos e para-corporativos imposta às forças vivas da "nação" a partir de 1933. O império da ideologia, os infindáveis textos doutrinários e a obsessão historiográfica de apurar em que medida o dogma corporativista gerou um sistema político e de representação de interesses realmente corporativo, parecem inibir a análise dos usos económicos da ideia corporativa e o estudo dos seus impactos sociais. Para tanto, falta estudar a prática das instituições corporativistas, cartografar os sectores económicos onde foram forçadas de modo vertical e horizontal e tipificar os seus impactos. Avanços que, estranhamente, a historiografia portuguesa não fez, após o fulgor dos anos setenta e oitenta do século XX.

Nos limites deste texto, propomos um debate preliminar sobre esta agenda de investigação, em especial sobre os sentidos da "economia corporativa portuguesa", expressão ambígua quanto baste. Pretende-se uma introdução ao tema e às problemáticas que ele encerra, exercício assente em três questôes:

a) Como estudar o corporativismo? A semântica corporativa: conceitos e ilusões doutrinais.

b) Como renovar o estudo histórico do «corporativismo português»?

c) Tópicos para um programa de investigação em História Económica e das Instituições centrado no tema da «economia corporativa portuguesa».

\section{O corporativismo português - uma fraude com relevância histórica}

Philippe Schmitter, no seu conhecido ensaio redigido nos anos setenta do século XX, advertiu sobre a tentação de ignorarmos o corporativismo português pelo simples facto de ele ter sido "anacrónico e irrelevante» 5 . «Se o fizéssemos», acrescenta o sociólogo americano, "estaríamos a ir ao encontro daqueles que já chegaram à conclusão de que o Estado corporativo de Mussolini não passava de uma aldrabice, bem como daqueles que insistem em levar o corporativismo a sério como se fosse um autêntico tertium genus entre o capitalismo e o socialismo".

Nem uma coisa nem outra, com certeza. Na verdade, o corporativismo português — que sempre se anunciou "associativo» ou "autodirigido» - foi uma fraude: primeiro porque apenas existiu enquanto "corporativismo de Estado", conforme diversos autores concluíram e, antes deles, alguns doutrinadores do próprio sistema; segundo, porque as corporações, órgãos de cúpula de um verdadeiro sistema corporativo, levaram mais de vinte anos a serem criadas e quando o foram (em 1956-57) pouco funcionaram; por último e em síntese, porque o carácter corporativo do Estado Novo, solenemente vertido na Constituição, foi apenas uma veleidade, decerto resultante da necessidade de achar um móbil moderadamente revolucionário para o novo regime.

5 Philippe Schmitter, Portugal: do Autoritarismo à Democracia, Lisboa, Imprensa de Ciências Sociais, 1999 , p. 166. 
Afinal, mais do que uma ideologia de legitimação da indecisa Ditadura Militar de 1926-1933, o "corporativismo português» cedo mostrou o que era e ao que vinha: um dispositivo de consolidação do regime autoritário, um recurso de dominação e arbitragem de interesses, um precioso instrumento de arrumação da "economia nacional» 6 . De uma economia nacional dita "corporativa», mas dominada por diversas formas de regulação económica estatal. Nesse intervencionismo dirigista sobressaíram os organismos de coordenação económica, elementos de administração indirecta do Estado que, embora anunciados como provisórios e nessa medida "pré-corporativos», acabaram por ter uma vida mais longa do que os próprios organismos corporativos ${ }^{7}$. Como concluiu Vital Moreira, a organização corporativa acabou por ser apenas um modo marginal de regulação, um instrumento auxiliar da coordenação económica estatal ${ }^{8}$.

Perante estes argumentos, justificar-se-ia que os historiadores cultivassem um certo desdém pelo tema. Mas a verdade é que, no caso português o corporativismo foi uma «fraude», mas uma «fraude» de grande relevância histórica na medida em que o sistema e a organização persistiram enquanto o regime durou. Ou seja: porque em nome do "Estado corporativo» foram criadas dezenas de instituições oficiais de organização da vida económica e social da nação que, na maioria dos casos, existiram e funcionaram durante cerca de quarenta anos.

Sem contrariar estes raciocínios, Manuel de Lucena salientou que «o acento tónico da organização corporativa portuguesa está na economia, que bate e de longe todos os outros sectores organizados»? .

O juízo é claro e certeiro conquanto resiste à prova empírica. Portugal conheceu uma organização económica estatal de sugestôes corporativas muito aquém do anunciado «Estado Corporativo», que acima de tudo serviu para reprimir conflitos sociais de natureza classista e para prevenir o confronto aberto dos interesses. Em rigor, o "Estado de ordem» português — liberal na economia, antiliberal na política —, achou nas ideias e instituições corporativas um expediente para se erguer e durar. Daí que nos pareça mais rigoroso considerar que o Estado Novo criou e impôs uma ordem económica corporativa.

Importaria discutir por que razões estas evidências e o apelo de estudo que supõem não alimentaram mais estudos sobre o corporativismo económico salazarista. À semelhança de outras problemáticas da historiografia dedicada ao Estado Novo português, também os estudos sobre o corporativismo começaram pelas grandes sínteses sem que se tivessem feito trabalhos prévios de análise, estudos sectoriais ou mesmo monográficos ${ }^{10}$.

\footnotetext{
${ }^{6}$ Em perspectivas divergentes, vide Fernando Rosas, O Estado Novo nos Anos Trinta, 1928-1938, Lisboa, Editorial Estampa, 2a ed., 1996, pp. 268-274; Nuno L. Madureira, A Economia dos Interesses. Portugal entre as Guerras, Lisboa, Livros Horizonte, 2002, pp. 31-71.

${ }^{7}$ Ver Vital Moreira, ob. cit., pp. 137-144; Manuel de Lucena, "A herança de duas revoluções: continuidade e rupturas no Portugal post-salazarista", in Mário Baptista Coelho (coord.), Portugal, O Sistema Politico e Constitucional, 1974-1987, Lisboa, ICS, 1989, pp. 505-555.

${ }^{8}$ Vital Moreira, ob. cit., p. 233.

${ }^{9}$ Manuel de Lucena, ob. cit., vol. I, p. 162.

10 Algumas excepções não desmentem a regra: nos domínios da agricultura, vide, entre outros, os ensaios monográficos de Manuel de Lucena: «Sobre a evolução dos organismos de coordenação económica ligados à lavoura», Análise Social, n. ${ }^{\text {os } 56-58, ~ 1978-1979 ; ~ " S a l a z a r, ~ a ~ f o ́ r m u l a ~ d a ~ a g r i c u l t u r a ~ p o r t u g u e s a ~ e ~}$
} 
$\mathrm{O}$ «corporativismo económico português» — fiquemo-nos por esta perspectiva um tanto redutora, porém mais próxima da realidade histórica invocada - supõe um imenso novelo, composto por muitas linhas ensarilhadas: Teoria, Doutrina, Leis, Instituições, Política, Economia, Sociedade... E seria possível, ainda, desagregar o termo corporativismo e as suas históricas realidades em outras tantas categorias analíticas: Ideologia, Sistema, Organização, Interesses.

Por detrás desta diversidade teórica, obviamente esquemática mas bastante expressa na infindável produção de textos construídos pelos próprios corporativistas (fossem eles conhecidos doutrinadores preocupados com a autenticidade do sistema, fossem obscuros compositores de vulgatas da «ideia corporativa»), espreitam algumas questôes essenciais. Perguntas pouco novas, é certo, mas relevantes para o entendimento do contexto histórico de aplicação das ideias corporativas: os nexos que se estabeleceram entre a «questão social» e a «crise do Estado liberal» na conjuntura internacional de problemas económicos e financeiros que acompanhou a Grande Guerra e boa parte de década de vinte; as relaçôes entre nacionalismo, fascismo e corporativismo; o advento do intervencionismo económico estatal ligado à administração pública das subsistências, da vida económica em geral e à definiçãao de políticas deflacionistas no após-guerra; por último, o Estado liberal (monarquias parlamentares ou repúblicas) perante a necessidade de intervir nos sistemas de intermediação de interesses, sobre os grupos organizados e oligarquias económicas - o refazer das relações entre o público e o privado como pilar da reconstrução autoritária ou totalitária dos Estados.

Numa expressão elucidativa do sentido pragmático com que a ideia corporativa serviu o projecto de reconstrução do Estado (a edificação do «Estado Novo»), Salazar sugeriu em 1933 que uma das tarefas da «República corporativa» seria a de amarrar os interesses ao Estado para reconstituir a autoridade pública ${ }^{11}$.

No caso português, a temática do sistema corporativo foi das primeiras a contribuir para uma historiografia do Estado Novo e para o entendimento da sua arquitectura política e institucional. No entanto, a análise histórica dos processos de institucionalização da teoria e doutrina corporativas continua a ser escassa e intermitente, como se tratasse de um tema bolorento ou «menor» para a historiografia moderna do Estado Novo.

Uma simples pesquisa bibliográfica evidencia um claro predomínio de estudos sobre o corporativismo enquanto sistema político e ideológico, perspectiva especialmente cuidada nos ensaios de Philippe Schmitter. Mais raros são os trabalhos dedicados ao corporativismo enquanto sistema económico e institucional de condução da vida económica e social, ou seja, de estatização nacional da economia e da própria

a intervenção estatal no sector primário", Análise Social, vol. XXVI, n. ${ }^{\circ} 110,1991$. Numa perspectiva de história social do corporativismo agrário do Estado Novo, vide a dissertação de Doutoramento em História Económica e Social Contemporânea apresentada por Dulce Freire à Universidade Nova de Lisboa: Portugal e a terra. Itinerários de modernização da agricultura em Alpiarça na segunda metade do século XX, Lisboa, 2008. Para o sector das pescas, ver A. Garrido, O Estado Novo e a Campanha do Bacalhau, cit.; Economia e Politica das Pescas Portuguesas, Lisboa, ICS, 2006.

${ }^{11}$ Cit. por Nuno L. Madureira, ob. cit., p. 51. 
sociedade ${ }^{12}$. Ressalvem-se os preciosos trabalhos de Manuel de Lucena, em parte já citados, que conjugam a perspectiva política, jurídica e institucional e reúnem preciosas intuições interpretativas sobre outras faces do sistema corporativo português. No plano da teoria económica e da doutrina que lhe está associada, destacam-se as sínteses de J. M. Brandão de Brito e de Carlos Bastien e, mais recentemente, os ensaios de José Luís Cardoso.

Por ora, apenas nos interessa partilhar um conjunto de reflexões capazes de cercar o problema historiográfico do corporativismo português e, a partir daí, esboçar um programa de investigação sobre a «economia nacional corporativa» entre 1933 e 1974 — ideologia, circunstâncias e instituições.

Algumas questôes prévias que colocámos encontram resposta consistente na historiografia internacional relativa aos fascismos que também se disseram corporativos. O programa de estudo é demasiado vasto, mas indispensável para se entender o contexto de formação dos "corporativismos históricos», bem como o recurso a aparelhos institucionais de inspiração corporativista para subordinar a economia e a sociedade à esfera da política — ao Estado investido em guardião do «interesse nacional».

O mesmo se pode dizer da historiografia portuguesa referente ao Estado Novo, cujo arranque, ainda em pleno marcelismo - uma coincidência que tem mais que se lhe diga e que, em certos casos, não fugiu à tendência neocorporativista que marcou as sociais-democracias do tempo - elegeu a problemática do corporativismo como prioridade. Não apenas porque boa parte das fontes históricas eram (e são) compostas por Leis, documentação relativamente fácil de reunir e consultar — assim optou Manuel de Lucena na sua mémoire de fin d'études apresentada ao Institut des Sciences Sociales du Travail de Paris, em 1971, publicada em 1976 - e de Philippe Schmitter, que em 1971 rumou a Portugal a fim de estudar, segundo o próprio sociólogo americano, "um caso de paleontologia política»: o "corporativismo de Estado» português que, embora imposto na década de trinta, sobrevivera ao desfecho da Segunda Guerra Mundial e resistira à morte de Salazar, inclusivamente com promessas de reforma no âmbito do «Estado social» imaginado por Marcelo Caetano ${ }^{13}$.

\section{O Estado Novo - uma «República corporativa», uma «economia nacional corporativa»}

O carácter corporativo do Estado Novo sempre foi apontado, quer pelos doutrinadores do sistema, quer por quantos o tomaram como matéria de estudo, como a principal singularidade do "fascismo português».

A título de argumento, basta enunciar dois factos; um de natureza discursiva; outro de ordem prática, aliás estruturante da organização económica e social que o Estado Novo plasmou de influências estrangeiras e impôs à Nação a fim de a organizar e subordinar:

12 Como também reconheceu Howard Wiarda, "Corporativismo", in A. Barreto e M. Filomena Mónica (coord.), Dicionário de História de Portugal, vol. VII, Porto, Figueirinhas, 1999, p. 422.

13 Cf. P. Schmitter, ob. cit., pp. 103-178. 
1) A proclamação constitucional do Estado como «República unitária e corporativa» (art. $5^{\circ}$ da Constituição plebiscitada em 1933);

2) $\mathrm{O}$ anúncio constitucional e para-constitucional ${ }^{14}$ do modelo económico corporativo; ou seja a fórmula doutrinária da "economia dirigida», solução política de «terceira via» entre o colectivismo socialista e o liberalismo individualista.

Para os fins deste debate, é o corporativismo económico, ou a mobilização da teoria e doutrina corporativas para a experiência histórica de institucionalização da "economia nacional de base corporativa» ${ }^{15}$ definida por Salazar em 1933 que importa considerar.

Alguns teóricos do sistema português, a exemplo de J. J. Teixeira Ribeiro, e a espaços a própria propaganda, preferiram a expressão mais realista de "economia dirigida" para designar a solução política de síntese — não propriamente de superação — entre liberalismo e socialismo. Em nosso entender, o corporativismo português não gerou uma economia corporativa autodirigida, mas uma economia dirigida ou uma economia institucionalizada de sugestôes corporativas.

A par da liquidação do sindicalismo livre e da corporativização do «trabalho nacional» (tarefas iniciadas em 1933), a disciplina dos mercados e a organização compulsiva dos sectores económicos mais atingidos pela crise internacional, ou mais capazes de reclamarem a protecção do Estado (decisões negociadas em plena Ditadura Militar, sobretudo a partir de 1929), foram as prioridades do plano corporativo de Salazar. Esse processo sinuoso fez-se, sobretudo, através da cartelização corporativa, uma contradição de termos, visto que a doutrina sempre anunciara uma sociedade organizada em corporações de carácter não público, ou seja, um «corpo social» composto por órgãos de cúpula constituídos por iniciativa dos interessados, em boa comunhão entre «capital» e "trabalho».

$\mathrm{Na}$ prática, a corporativização da economia portuguesa nunca se verificou. Não houve uma economia corporativa portuguesa no plano teórico; nem tão-pouco ela existiu no plano prático, ou no terreno institucional fertilizado pela ideologia corporativa. O Estado Novo consentiu, na realidade, uma economia liberal menos estatizada do que aquela que o país conhecera durante a I República. No entanto, o paradoxo só é válido se o tomarmos no plano formal.

O Estado Novo não moldou uma «economia nova»; antes impôs uma economia dirigida e intervencionada, que se serviu da doutrina corporativa para criar instituiçôes reguladoras dos conflitos de interesse. Tratou-se de impor uma miríade de organismos capaz de prevenir movimentos de acção colectiva conotados com a pregação marxista da luta de classes.

\footnotetext{
14 Referimo-nos, respectivamente, à Constituição de 1933 e à série de seis «decretos corporativos» assim a propaganda os designou - de 23 de Setembro do mesmo ano: Estatuto do Trabalho Nacional, Grémios Obrigatórios, Sindicatos Nacionais, Casas do Povo, Casas Económicas, Instituto Nacional do Trabalho e Previdência.

15 Menos categórica do que as expressões "economia nova» ou "economia corporativa», a expressão pertence a J. J. Teixeira Ribeiro, Princípio e Fins do Sistema Corporativo Português, Coimbra, Coimbra Editora, 1939.
} 
Ainda assim, nenhum destes desvios e contradições do sistema corporativo português retira interesse ao estudo das respectivas instituições.

Como salientou Philippe Schmitter, o corporativismo foi a pedra angular de um regime autoritário ultra-institucionalizado ${ }^{16}$. Os grémios obrigatórios da lavoura, da indústria e do comércio, bem como os «sindicatos corporativos» dos mais diversos sectores do trabalho, serviram o propósito do Estado de criar um sistema horizontal de representação de interesses e uma rede vertical e horizontal de controlo político do «capital» e do «trabalho».

Esta errática e gigantesca tarefa, executada por lei entre 1932 e os últimos anos da Guerra de 1939-1945, resultou na imposição de cerca de três dezenas de organismos de coordenação económica (na prática eram serviços públicos que nada tinham de corporativos) a sectores vitais da exportação e importação de bens agrícolas e alimentares. A substituição parcial das importaçôes de subsistências cujas produçôes nacionais eram cronicamente deficitárias e a garantia de importação de matérias-primas indispensáveis à indústria transformadora impeliram o Estado a fazer desses sectores "estratégicos» (e vulneráveis ao impacto de crises externas) domínios prioritários da intervenção pública. A «economia dirigida» mostrou-se, assim, tanto mais densa quanto as actividades económicas em questão mobilizaram o Estado autoritário a escudar-se numa economia política tendencialmente autárcica.

Os organismos de coordenação económica criados sob a égide do Estado nos sectores primário e secundário receberam poderes de "comércio de Estado", incumbências de diplomacia económica e prerrogativas de intervenção nos mercados dos respectivos produtos; foram-lhes atribuídas competências arbitrais sobre conflitos intra-sectoriais de interesse nas respectivas fileiras da «economia nacional»; foram-lhes cometidos poderes de regulação e fiscalização vertical das produções, do comércio e, nalguns casos, de fixação de preços administrativos.

\section{Uma economia nacional de base corporativa?}

Uma das ilusões mais comuns do corporativismo fascista - um composto de ideias sociais e políticas com cambiantes nacionais, pese a influência do arquétipo italiano - consiste na sugestão de uma fórmula política supraliberal, capaz de salvar o sistema capitalista de si próprio e de resolver a «questão social» por meio de formas associativas e espontâneas de organização dos interesses.

Nas suas pretensōes regeneradoras do sistema capitalista-liberal, a teoria económica corporativa chegou a pugnar por um homo corporativus, uma nova condição da natureza humana capaz de garantir uma ordem económica e social fundada na comunhão entre o indivíduo e o Estado. Este último argumento doutrinal não só permitiu reafirmar a supremacia do conceito de «economia nacional» — colhido na velha escola histórica alemã de Economia Política, em especial na obra de Friedrich List $^{17}$ —,

16 P. Schmitter, ob. cit., p. 104 e pp. 132-142.

17 Vide Geoffrey M. Hodgson, How Economics forgot History. The problem of historical specificity in Social Science, London and New York, Routledge, 2001, pp. 56-64. 
como serviu para declarar a ordem corporativa a única fórmula político-institucional do «bem-estar colectivo».

Como notou Brandão de Brito, a grande preocupação dos teóricos do corporativismo português foi a defesa do princípio da concorrência imperfeita ${ }^{18}$. Nesta acepção simultaneamente dogmática e pragmática, a organização corporativa seria o instrumento ideal e necessário para um forte intervencionismo do Estado na vida económica.

Autoritário e oligárquico, o sistema corporativo português ofereceu ao Estado em reconstrução um instrumento capaz de refazer as relaçōes entre o público e o privado e impor uma vasta gama de instituições de intermediação dos interesses. Como o próprio Salazar admitiu, a conciliação arbitrada dos interesses teria por fim amarrá-los ao Estado através de negociaçôes oligárquicas que, em boa parte, ainda decorreram no interior das associaçôes patronais da era liberal. Acordos mais ou menos informais, foram feitos caso a caso e conforme os impactos da crise do capitalismo em cada sector da "produção nacional». Em moldes semelhantes, embora mais em surdina, essas negociações e favoritismos prosseguiram no interior dos grémios corporativos, nos avatares burocráticos do condicionamento industrial e nos corredores dos próprios ministérios ${ }^{19}$.

Como foi dito, os doutrinadores mais relevantes e prudentes do sistema (na sua maioria, professores de Direito das universidades de Lisboa e Coimbra) chamaram a essa fórmula de organização oligárquica e autoritária do Estado e de intervenção num sistema capitalista atingido por sérios problemas no comércio internacional de bens e capitais, "economia dirigida" ou "economia dirigida de base corporativa». Deste modo, a doutrina oficial procurou demarcar a relação do Estado Novo com a vida económica dos modelos estatizados colectivistas e tentou conter o entusiasmo dos salazaristas que exaltavam categoricamente uma "economia corporativa» inspirada nos teóricos do fascismo italiano 20 .

Estas e outras promessas vãs da doutrina e propaganda acabaram por ser denunciadas por destacadas figuras do regime salazarista. No caso português, diversos corporativistas que durante a década de trinta se haviam destacado como ideólogos e doutrinadores, depressa se desiludiram. Além da incumprida promessa do «Estado corporativo» - que nunca o foi, não obstante a existência de uma Câmara Corporativa no sistema político do regime ${ }^{21}$ —, alguns salazaristas insuspeitos verberaram o des-

18 J. M. Brandão de Brito, A Industrialização Portuguesa no pós-guerra (1948-1965). O Condicionamento Industrial, Lisboa, Publicações Dom Quixote, 1989, pp. 99-109.

19 Observámos detidamente estes processos relativamente às "pescas nacionais corporativas»: A. Garrido, O Estado Novo e a Campanha do Bacalhau, cit.; Henrique Tenreiro: uma Biografia Política, Lisboa, Círculo de Leitores/Temas \& Debates, 2009, em especial, pp. 220-251.

${ }^{20}$ Os autores portugueses (que não deixaram de ser doutrinadores) que mais se esforçaram por teorizar a "economia corporativa" foram João Pinto da Costa Leite (Lumbralles), José Joaquim Teixeira Ribeiro e, em parte, o próprio Marcelo Caetano, essencialmente um ideólogo e redactor de doutrina. Cf. J. M. Brandão de Brito, ob. cit., p. 99 e ss.; Carlos Bastien e J. L. Cardoso, «From homo economicus to homo corporativus: A neglected critique of neoclassical economics", The Journal of Socio-Economics, 36, 2007, p. 120.

21 Sobre o papel da Câmara Corporativa no sistema político do Estado Novo, foi apresentada recentemente uma dissertação de Doutoramento, em Sociologia Política, no Instituto de Ciências Sociais da Universidade de Lisboa: Nuno Estêvão Ferreira, A Câmara Corporativa no Estado Novo: Composição, Funcionamento e Influência, 2 vols., Lisboa, 2009. 
lize do sistema para as autoritárias e pouco corporativas funções de intervenção do Estado na economia e para a colaboração forçada dos interesses dentro de instituições de direito público 22 .

\section{Economia corporativa ou economia institucionalizada?}

Na prática, o corporativismo português não gerou uma economia corporativa, mas uma economia dirigida ou institucionalizada. Por outras palavras, segundo Vital Moreira, o que realmente existiu foi «uma ordem económica estatal com uma componente corporativa» ${ }^{23}$. Significa que não houve organização corporativa dos interessados, mas uma institucionalização das relações sociais e económicas dentro de entidades públicas e semi-públicas impostas pelo próprio Estado — organismos de coordenação económica, grémios facultativos, obrigatórios e federaçôes gremiais, sindicatos nacionais, casas do povo e casas dos pescadores.

Imposição legalista e burocrática, foi conduzida sem pudores de coerência com os ideais doutrinários que, na sua maioria, exprimiam o "corporativismo das encíclicas», ou a escola social-cristã do pensamento corporativista formado no século XIX. Em lugar desse corporativismo ideal e associativo, no campo económico e social Salazar permitiu a construção pouco planeada de um corporativismo fascista e secular, autoritário e burocrático, muito próximo da síntese crítica de Mihail Manöilesco, dos escritos do sociólogo austríaco Othmar Spann e dos economistas italianos Giuseppe Bottai e Ugo Spirito.

Apesar dos esforços de alguns professores portugueses, a teoria económica corporativa nunca se afirmou como modelo ${ }^{24}$. A partir de 1949 , coabitou como pôde com o keynesianismo, cujas ideias começaram a fazer escola em Portugal.

Eclética e pragmática, a economia corporativa portuguesa mostrou-se uma composição frágil de referências colhidas em diversas correntes do pensamento económico. Uma síntese com escassa autonomia teórica em relação ao paradigma neoclássico que servira a ordem económica liberal, cujas noções de "concorrência perfeita», «equilíbrio espontâneo dos mercados» e «bem-estar individual», os corporativistas criticaram com veemência. Além disso, em Portugal como no estrangeiro a ideologia económica corporativa permaneceu presa a um discurso doutrinário construído em torno do dogma do "interesse nacional», a tradução política da noção ética de "utilidade social colectiva» 25 .

22 Entre outros, o próprio Marcelo Caetano, num conhecido opúsculo, resultante de uma conferência proferida a 23 de Março de 1950 no Gabinete de Estudos Corporativos: Posição actual do corporativismo português, Lisboa, Império, 1950.

23 Vital Moreira, ob. cit., p. 232.

${ }^{24}$ Cf. Carlos Bastien, Para a História das Ideias Económicas no Portugal Contemporâneo. A Crise dos anos 1945-1954, Lisboa, Instituto Superior de Economia da Universidade Técnica de Lisboa, 1989, vol. I, p. 183 e ss.

25 J. L. Cardoso, História do Pensamento Económico Português. Temas e Problemas, Lisboa, Livros Horizonte, 2001, p. 35. 
De acordo com a visão pragmática que Salazar amiúde exprimiu do corporativismo, a teoria e os princípios do sistema serviram, acima de tudo, para dar ao processo de institucionalização da vida económica e social - a colaboração dos interesses e a conciliação forçada do "capital» e do "trabalho» - uma lógica de arrumação que pudesse ser feita por via legislativa e burocrática.

As reformas orçamental, fiscal e do crédito impostas em 1928-29 pelo ministro das Finanças Oliveira Salazar, a revisão dos mecanismos de protecção pautal definida em 1929, o condicionamento industrial e a liquidação do sindicalismo associativo foram os demais instrumentos da construção autoritária de uma economia institucionalizada de sugestôes corporativas. Esta, por sua vez, parece ter sido causa e efeito da construção de um Estado autoritário fortemente oligárquico e de sugestóes fascistas.

\section{Questóes em aberto para um programa de investigação}

A fim de discutirmos em profundidade a validade classificativa da expressão economia institucionalizada de sugestôes corporativas, importa colocá-la à prova num projecto de investigação em história das instituiçôes económicas do corporativismo português. As perguntas fundamentais desse programa de estudo parecem-nos as seguintes:

a) Que nexos se estabeleceram entre o "Estado corporativo» e a "economia nacional corporativa»? Teoria, doutrina e discurso político-legislativo — um inventário de fontes.

b) A institucionalização da "economia nacional corporativa» significou uma ruptura com os princípios e práticas da economia liberal?

c) Que relaçôes se identificam entre a teoria económica corporativa, a doutrina e a arquitectura institucional (o sistema e a organização)?

d) Quais os processos típicos de implementação da ordem económica corporativa?

e) Que perfis institucionais dominaram a economia dirigida portuguesa? Uma cartografia por sectores; um mapa dos perfis institucionais de regulação/ intervenção (matrizes, correlações e regularidades) ${ }^{26}$.

f) Que relações se estabeleceram entre a construção da "previdência corporativa» e a organização económica e social corporativa? Uma análise sumária da vida financeira da organização corporativa.

g) Como aferir o peso absoluto e relativo do sector público-corporativo da economia portuguesa entre 1933 e 1974 ?

A historiografia sobre o corporativismo português e a resposta ao leque de perguntas que colocámos levam-nos a supor que a institucionalização da ordem económica corporativa e a acção duradoura e persistente das suas instituiçôes concorreram decisivamente para a longevidade da ditadura. Do mesmo modo, a «economia

26 Para um apoio à identificação de fundos documentais, além do Arquivo Histórico do Tribunal de Contas e de diversas publicaçôes institucionais da extinta Organização Corporativa, sugere-se a consulta do seguinte estudo: Diagnóstico aos Arquivos Intermédios da Administração Central, Lisboa, Observatório das Actividades Culturais/Instituto dos Arquivos Nacionais/Torre do Tombo, 2003. 
corporativa» fortaleceu os nexos entre o sistema político autoritário, a economia dita «nacional» nos seus sectores mais débeis e carentes de protecção e uma vida social muito inibida nos seus movimentos devido à asfixia que o corporativismo oligárquico sobre ela exerceu.

Mais do que insistir na história das oposiçôes ao Estado Novo, questão sem dúvida relevante mas insuficiente, e no estudo dos processos de abertura do regime ao exterior, a historiografia do Estado Novo poderá renovar a sua agenda se, em vez de se privilegiar os avatares da memória, tiver a audácia de abordar a herança ditatorial na sua própria historicidade.

Nesta perspectiva — voltando a sublinhar que o corporativismo foi a única ideologia declarada na Constituição de 1933 — o estudo da acção concreta das instituições corporativas e para-corporativas deverá voltar ao primeiro plano da historiografia do Estado Novo. Lugar que significativamente ocupou durante os seus primórdios, enquanto história crítica de um passado que finalmente prescrevia.

Volvidos trinta e cinco anos do fim da ditadura de Salazar e Caetano, o conhecimento histórico do Estado Novo teima em colocar-nos a mesma trilogia de problemas que o animou nas décadas de oitenta e noventa do século XX: 1) As origens ideológicas e sociais do regime e os seus processos de implantação no âmbito da crise do Estado liberal; 2) A natureza política do Estado Novo no contexto histórico dos fascismos da Europa de entre-guerras; 3) A extraordinária longevidade da ditadura portuguesa e a sua resistência às transformaçōes externas e internas.

Se é certo que tudo cabe neste triângulo de questões, não é menos verdade que a "questão corporativa», ou a construção do sistema corporativo português nas suas singularidades e paradoxos, emerge em qualquer uma destas problemáticas.

A história contemporânea é, com frequência, uma história de ideias em movimento. Por estática e estrutural que pareça, a «ideia corporativa» foi um campo de ensaio social e uma moldura económica muito debatida e controversa: proclamada e logo deturpada, essencial mas falsa, necessária, porém contingente. Estudá-la nos contextos sócio-institucionais onde o corporativismo foi imposto e vivido com consentimento ou resistência significa tentar compreender o Estado Novo nas suas estruturas mais crípticas e complexas, entre a ideologia e a prática, entre o dogma e a realidade.

\section{BIBLIOGRAFIA}

Bastien, Carlos, Para a História das Ideias Económicas no Portugal Contemporâneo. A Crise dos anos 1945-1954, 2 vols., Lisboa, Instituto Superior de Economia da Universidade Técnica de Lisboa, 1989 (Dissertação de Doutoramento em Economia, policopiada).

BASTIEN, Carlos; Cardoso, José Luís, «From homo economicus to homo corporativus: A neglected critique of neoclassical economics», The Journal of Socio-Economics, 36, 2007.

BRITO, José Maria Brandão de, A Industrialização Portuguesa no pós-guerra (1948-1965). O Condicionamento Industrial, Lisboa, Publicações Dom Quixote, 1989.

Caetano, Marcelo, Liçôes de Direito Corporativo, Lisboa, 1935.

—, Posição actual do corporativismo Português, Lisboa, Império, 1950.

—, O Sistema Corporativo, Lisboa, 1938. 
Cardoso, José Luís, História do Pensamento Económico Português. Temas e Problemas, Lisboa, Livros Horizonte, 2001.

Fernandes, António de Castro, O Corporativismo Fascista, Lisboa, Editorial Império, 1938.

Ferreira, Nuno Estêvão, A Câmara Corporativa no Estado Novo: Composição, Funcionamento e Influência, 2 vols., Lisboa, Instituto de Ciências Sociais da Universidade de Lisboa, 2009 (Dissertação de Doutoramento em Sociologia Política, policopiada).

FreIRE, Dulce, Portugal e a terra. Itinerários de modernização da agricultura em Alpiarça na segunda metade do século XX, Lisboa, Universidade Nova de Lisboa, 2008 (Dissertação de Doutoramento em História Económica e Social Contemporânea, policopiada).

Garrido, Álvaro, Economia e Política das Pescas Portuguesas, Lisboa, Imprensa de Ciências Sociais, 2006.

—, O Estado Novo e a Campanha do Bacalhau, Lisboa, Círculo de Leitores, 2004.

-, Henrique Tenreiro: uma Biografia Política, Lisboa, Círculo de Leitores, 2009.

Hodgson, Geoffrey M., How Economics forgot Economics. The problem of historical specificity in Social Science, London and New York, Routledge, 2001.

LuCEnA, Manuel de, A evolução do sistema corporativo português, 2 vols., Lisboa, Perspectivas \& Realidades, 1976.

—, "A herança de duas revoluções: continuidade e rupturas no Portugal post-salazarista», in Mário Baptista Coelho (coord.), Portugal, O Sistema Politico e Constitucional, 1974-1987, Lisboa, ICS, 1989.

—, "Salazar, a fórmula da agricultura portuguesa e a intervenção estatal no sector primário», in Análise Social, vol. XXVI, n. ${ }^{\circ} 110,1991$.

—, "Sobre a evolução dos organismos de coordenação económica ligados à lavoura», in Análise Social, vols. XIV-XV, n. ${ }^{\text {os }}$ 56-58, 1978-1979.

Madureira, Nuno Luís, A Economia dos Interesses. Portugal entre as Guerras, Lisboa, Livros Horizonte, 2002.

MANÖILESCO, Mihail, Le sécle du corporatisme: doctrine du corporatisme intégral et pur, Paris, Félix Alcan, 1934.

Michelis, G. de, La Corporation dans le Monde. Économie Dirigée Internationale, Paris, Les Éditions Denoel et Steele, 1935.

Moreira, Vital, Auto-Regulação Profissional e Administração Pública, Coimbra, Almedina, 1997.

PatriarCA, Fátima, A Questão Social no Salazarismo, 1930-1947, 2 vols, Lisboa, Imprensa Nacional Casa da Moeda, 1995.

Pereira, Pedro Teotónio, A Batalha do Futuro. Organização Corporativa, 2 a ed., Lisboa, Livraria Clássica Editora, 1937.

Ribeiro, José Joaquim Teixeira, Principio e Fins do Sistema Corporativo Português, Coimbra, Coimbra Editora, 1939.

Rosas, Fernando, O Estado Novo nos Anos Trinta, 1928-1938, Lisboa, Editorial Estampa, 2a ed., 1996.

—, Portugal siglo XX (1890-1976). Pensamiento y acción política, Mérida, Junta de Extremadura, 2004.

—, Salazarismo e fomento económico (1928-1948), Lisboa, Editorial Notícias, 2000.

SChmitter, Philippe C., Portugal: do Autoritarismo à Democracia, Lisboa, ICS, 1999.

TORGal, Luís Reis, Estados Novos Estado Novo, 2 vols., Coimbra, Imprensa da Universidade de Coimbra, 2009.

—, Marcelo Caetano antes do Marcelismo, col. "Cadernos do CEIS20», Coimbra, CEIS20, 2007.

Wiarda, Howard, Corporatism and development: the Portuguese experience, Amherst, The University of Massachussets, 1977.

—, "Corporativismo», in A. Barreto e M. Filomena Mónica (coord.), Dicionário de História de Portugal, vol. VII, Porto, Figueirinhas, 1999. 
Série

Documentos

Imprensa da Universidade de Coimbra

Coimbra University Press

2010

- U

C • 